\title{
DE-CONSTRUYENDO EL PASADO. SOBRE LA POTENCIA POLÍTICA Y LAS MEMORIAS AL MARGENDE LA COMUNIDAD LGTB EN ARGENTINA
}

\author{
DES-CONSTRUINDO O PASSADO. \\ SOBRE A POTÊNCIA POLÍTICA E AS MEMÓRIAS À MARGEM DA COMUNIDADE LGTB \\ NA ARGENTINA
}

\author{
Ludmila da Silva Catela ${ }^{1}$ \\ Eugenio Talbot Wright ${ }^{2}$
}

\begin{abstract}
RESUMEN: En este texto analizamos la temporalidad de las memorias diversas, sus momentos de visibilidad, de silencio y sus producciones de sentidos desde los márgenes. ¿Son memorias silenciadas, olvidadas, invisibles? ¿Cuáles fueron y son sus espacios de construcción? ¿Sus tiempos de visibilización coinciden con los de las memorias dominantes? Para esto proponemos tres momentos de análisis. El primero relativo al momento fundacional de una narrativa sobre la memoria, como fue el trabajo de la CONADEP y la cristalización de una memoria encuadrada (¿oficial, dominante, hegemónica?) a partir de la edición del libro Nunca Más. El segundo momento, propone una mirada hacia atrás en el tiempo para comprender como a partir de mediados de la década del 60 la comunidad "homosexual" (uso aquí la categoría nativa de la época) plasmó sus acciones políticas en el espacio público a partir de memorias disidentes y diversas. Finalmente, volveremos al presente para observar de qué manera estas memorias han ganado legitimidad y visibilidad a partir de la consigna 30400, para pensarlas como memorias insurgentes.

Palabras llaves: Memorias; diversidad; LGTB; Argentina.
\end{abstract}

\begin{abstract}
In this text I analyze the temporality of the various memories, their moments of visibility, silence and their productions of senses from the margins. Are they silenced, forgotten, invisible memories? What were and are its construction spaces? Do your visibility times coincide with those of the dominant memories? For this I propose three moments of analysis. The first related to the foundational moment of a narrative on memory, such as the work of CONADEP and the crystallization of a framed memory (official, dominant, hegemonic?) From the edition of the book Never Again. The second moment, proposes a look back in time to understand how from the mid-1960s the "homosexual" community (I use the native category of the time here) shaped its political actions in the public space from dissident and diverse memories. Finally, I will return to the present to observe how these memories have gained legitimacy and visibility from the slogan 30400, to think of them as insurgent memories.
\end{abstract}

Key words: Memories; diversity; LGTB; Argentina.

\footnotetext{
${ }^{1}$ Ludmila da Silva Catela. Mujer CIS. Doctora en Antropología Cultural por la Universidad Federal de Río de Janeiro, Brasil. Profesora e investigadora de la Universidad Nacional de Córdoba e Investigadora Independiente del CONICET en el IDACOR, Museo de Antropología-UNC.

${ }^{2}$ Eugenio Talbot Wright. Varón trans. Hijo de desaparecido. Militante de DDHH.
} 


\title{
Márgenes
}

\author{
"En español, margen, actualmente es masculino cuando \\ significa 'espacio en blanco alrededor de lo escrito' (el margen de la \\ página), 'espacio u ocasión para algo' (el margen de actuación, \\ el margen de confianza) y 'diferencia prevista' (el margen de beneficio, \\ el margen de error)". (Consultado en: \\ https://www.fundeu.es/consulta/el-o-la-margen-468/)
}

Si hacemos un breve juego con el significado de este sustantivo masculino podemos listar algunas ideas a partir de las cuales iniciar un recorrido analítico en torno a las memorias y sus márgenes. Por un lado, podemos pensar en la zona dónde se encuentra el límite de un lugar y allí pararnos para observar y descubrir memorias que se gestan y producen al margen de aquellas que dominan el espacio público. Ahora bien, si elegimos usar la metáfora de margen como orilla de un cauce de agua, el foco lo colocamos en el rastro que deja el agua cuando se retira, allí las memorias aparecen como huellas y restos de un pasado, que se encontraba invisibilizado. Si jugamos con la idea de margen como espacio en blanco, aquel que queda al costado de las páginas, podemos ampliarlo o reducirlo para generar nuevos lugares de escritura, para gestar más espacios de recuerdo y de narraciones. Si, finalmente, nos apropiamos de la idea de espacio figurado, podemos seguir su camino para observar que ya no hay margen para que se sigan silenciando las memorias disidentes y diversas.

Si la memoria organiza su trabajo sobre puntos visibles del recuerdo, pensar los márgenes nos permite una nueva oportunidad de construcción de preguntas sobre lo visible y lo invisibilizado. En este sentido, las memorias resistentes de la comunidad LGTB luchan por salir del margen al que fueron corridas desde el proyecto dominante de las memorias públicas, heteronormativas y hegemónicas sobre el pasado reciente de violencia política en Argentina. ${ }^{3}$

¿Cómo pensar los márgenes en los procesos de memoria? Si comenzamos por leer los márgenes de las memorias dominantes, observamos claramente que las memorias sobre la diversidad sexual están olvidadas y/o silenciadas. Hay aquí una cuestión de foco, ¿dónde las estamos observando? El problema que plantean estas memorias, como muchas otras que se construyeron "al margen" es que producen sus sentidos en circuitos de memorias subterráneas (POLLAK, 2006) y al no dominar el campo, no las vemos aunque luchen por imponerse en el espacio público. Ahora bien, ¿memorias al margen de qué? En las luchas por los sentidos del pasado, estas memorias no oficiales, se construyeron, sostuvieron y lucharon por ser oídas. Por ser incluidas dentro de otras memorias, que como en un juego de muñecas rusas son escondidas una y otra vez aunque cuando se despliegan están allí. Memorias silenciadas, sometidas, no escuchadas por las memorias dominantes y centrales. Memorias que aparecen acá y allá, que florecen por momentos y luego caen nuevamente en el olvido. Memorias que tienen su propio lenguaje. Sin embargo, esta constitución de memorias al margen, también expresan allí su potencialidad, ya que dejan abierta la posibilidad de poder incluirles nuevos sentidos. Margen, como metáfora de espacios a conquistar, permite pensar en zonas, oportunidades,

\footnotetext{
${ }^{3}$ Un análisis de estos silencios e invisibilizaciones de las memorias diversas puede leerse en el dossier, "Memorias desde las disidencias sexo-genéricas. Preguntas incómodas para desmontar el cisexismo heterosexual". Revista Aletheia, vol. 10. № 19, 2019.
} 
beneficios, personas y fundamentalmente diferencias que se expresarán, batallarán y potencialmente, lograrán imponer sus representaciones sobre el pasado y la violencia sobre sus cuerpos desde nuevas formas y variaciones de memorias.

Cuando comencé a investigar sobre los temas relativos a los procesos de construcción de memorias en Argentina, allá por mediados de los años noventa, la categoría no estaba instalada ni en el debate académico, ni en las organizaciones territoriales. ${ }^{4}$ El pasado reciente y el terrorismo de Estado se expresaban en el ámbito de la justicia, en las denuncias sobre las leyes de impunidad, en los rituales colectivos de las rondas en las plazas y las marchas del 24 de marzo. Hoy, podemos decir que cada diez años se renuevan ciclos de memoria que coinciden con las fechas redondas del 24 de marzo. 1986 (10 años) fue el momento de las Justicia, de la CONADEP, los informes sobre la violación a los derechos humanos, los testigos y testimonios sobre los centros clandestinos de detención, la tortura, la apropiación de niños, la desaparición de personas. 1996 (20 años de la dictadura) marcó la aparición de la organización de derechos humanos HIJOS y de una serie de nuevas preguntas sobre el pasado reciente. 2006 (30 años de la dictadura) inauguró un momento de "estatización de las memorias" con museos, sitios de memorias, archivos, políticas públicas educativas sobre memoria y pasado reciente. 2016 (40 años del golpe) inauguró una apertura sobre las formas de comprender el pasado, nuevos grupos sociales que se sumaron a las reivindicaciones de memoria, verdad y justicia y por supuesto nuevas demandas en torno a las luchas de género.

En este texto queremos analizar la temporalidad de las memorias del colectivo LGTB en Argentina, sus momentos de visibilidad y de silencio, sus producciones de sentidos desde los márgenes a partir de documentos púbicos, archivos y testimonios. ${ }^{5}$ Vale la pena organizar el recorrido a partir de una serie de preguntas, ¿Son memorias silenciadas, olvidadas, invisibles? ¿Cuáles fueron y son sus espacios de construcción? ¿Sus tiempos de visibilización coinciden con los de las memorias dominantes? Para esto proponemos tres momentos de análisis. El primero relativo al momento fundacional de una narrativa sobre la memoria sobre el terrorismo de Estado en Argentina, colocando el foco en el trabajo fundante de la Comisión Nacional de Desaparición de Personas (CONADEP) y la cristalización de una memoria encuadrada (¿oficial, dominante, hegemónica?) a partir de la edición del libro Nunca Más. ${ }^{6}$ El segundo momento, se centra en una mirada hacia atrás en el tiempo, para comprender como a partir de mediados de la década del 60 la comunidad "homosexual" (usamos aquí la categoría nativa de la época) plasmó sus acciones políticas en el espacio público a partir de memorias disidentes y diversas. Finalmente, volveremos al presente para observar de qué manera estas memorias han ganado legitimidad y visibilidad a partir de la consigna 30400, para pensarlas como memorias insurgentes que luchan por ganar sentidos frente a una mirada heteronormativa de los procesos de memoria.

\footnotetext{
${ }^{4}$ En los años noventa inicié mi trabajo de campo en la ciudad de La Plata con familiares de desaparecidos en torno a sus experiencias frente a la desaparición de sus seres queridos. Esa investigación dio lugar a mi tesis de doctorado que quedó editada en Da Silva Catela (2001).

${ }^{5}$ Este trabajo, a diferencia de otras investigaciones que se nutren del trabajo de campo, está basado en el análisis de documentos de archivos digitales, páginas web, noticias de diarios y revistas, recolección de testimonios de documentales. Los mismos son citados a lo largo del texto cuando son utilizados. Pero este trabajo está constituido también a partir de un diálogo con Eugenio Talbot Wright que iniciamos a partir de unas primeras líneas para la elaboración de este texto.

${ }^{6}$ El trabajo de la CONADEP y la edición del libro Nunca Más fundaron los cimientos de una mirada dominante sobre los acontecimientos de la dictadura militar Argentina (1976-1983). Para un análisis detallado sobre la historia política de esta Comisión ver Crenzel (2008).
} 


\section{Relato inaugural y memorias encuadradas}

El 15 de diciembre de 1983 fue creada la CONADEP, con el objetivo de investigar las graves, reiteradas y planificadas violaciones a los derechos humanos durante el período del terrorismo de Estado en Argentina. El objetivo de la comisión, como se expresa en su prólogo "no era juzgar, para eso están los jueces constitucionales, sino para indagar la suerte de los desaparecidos en el curso de estos años aciagos de la vida nacional" (Nunca Más, 1986, p.7). La comisión también relevó los lugares de detención y tortura, los tipos de vejámenes cometidos, la metodología clandestina de represión por parte de las fuerzas armadas argentinas. Receptó las denuncias sobre la apropiación de niños y sobre los delitos de robo y apropiación de la propiedad privada. La CONADEP construyó una manera nueva de investigación basada en procedimientos judiciales ya conocidos, el testimonio, la confección de expedientes para la denuncia individual, la recepción de la foto del desaparecido, el relevamiento testimonial y visual de los centros clandestinos de detención. Los comisionados - que fueron elegidos por ser referentes sociales, políticos, religiosos, culturales y sobre todo "personas respetadas" socialmente (12 hombres y 1 mujer) - recorrieron el país llevando adelante miles de entrevistas para recepcionar las denuncias. Luego sistematizaron todo en un Informe conocido como el Nunca Más, confeccionado en torno a casos "emblemáticos".

Entre sus integrantes estaban, como todos saben, Sábato (escritor), Favaloro (médico), Klimosvsky (matemático), Gattinoni (pastor evangélico), Meyer (Rabino estadounidense), De Nevares (monseñor católico), Rabossi (Filosofo), Colombres (abogado), Fernández Longo (Ingeniero), Magdalena Ruiz Guiñazu (periodista y única mujer de la comisión) y López, Piucilli y Huarte (diputados radicales en representación del Congreso). Nos detenemos en los nombres de la comisión ya que la constitución de la misma con personas "respetadas" de la sociedad argentina, marcó la manera en que la CONADEP se desarrolló, pero sobretodo da cuenta también del relato que construyó y la memoria que instituyó a partir del libro Nunca Más?

Este momento fundante, estableció una mirada determinada sobre el pasado de violación a los derechos humanos. En 180 días redactaron un informe que pasó a constituir "la verdad" sobre el terrorismo de Estado. Lo que se incluyó fue una selección que pasó por el tamiz de estos hombres y una mujer. Todos ellos citadinos, clases medias, profesionales, reconocidos en sus ámbitos de trabajo. Tres integrantes del mundo religioso. Ningún integrante obrero, campesino, indígena, habitantes de villa miserias, de comunidades de diversidades sexuales o étnicas. Este fue el primer trabajo de "encuadramiento" de la memoria sobre el pasado reciente, muy reciente si pensamos que fue en 1983. Lo que quedó plasmado en el informe de la CONADEP fue lo que pasó, el resto (lo que allí no quedó escrito) todavía hoy hay que comprobarlo. ${ }^{8}$ Es interesante pensar como esta gran narrativa sirvió y sirve actualmente

\footnotetext{
${ }^{7}$ El Libro Nunca Más. Informe de la Comisión Nacional sobre la Desaparición de Personas se publicó por primera vez en noviembre de 1984 por la editora de la Universidad de Buenos Aires, EUDEBA. En los primeros años de la transición democrática, desde su edición inicial en 1984 hasta 1986 se reeditó 14 veces.

8 A modo de ejemplo, cuando trabajé en el Archivo Provincial de la Memoria de Córdoba editamos un breve libro sobre los Centros Clandestinos de Detención de la provincia. El trabajo de investigación nos llevó a determinar que durante el período de la dictadura militar habían funcionado en Córdoba muchos más CCD de los que figuraban en la investigación de la CONADEP. Allí comenzó un debate en torno a cómo comprobaríamos aquellos que "no estaban" en el Nunca Más, lo cual llevó a una larga reflexión en torno a las nuevas denuncias y su incorporación en torno a las memorias dominantes. Por otro lado, en mi trabajo de campo en Jujuy en el NOA descubrí por medio de los testimonios que el relato sobre el caso del Apagón de Ledesma ligado al Ingenio Ledesma, plasmado en el Nunca Más contenía un error de fechas y de lugares de detención lo que motivó mi reflexión en relación al poder de la palabra escrita sobre los testimonios y las tensiones que esto conlleva. Escribí un texto en relación al poder de las memorias locales dónde reflexiono sobre dichas tensiones, da silva Catela (2003). Ese texto motivó algunas
} 
como validación para lo que sucedió después en el ámbito jurídico pero también en el campo social y en el movimiento de derechos humanos. Pero la pregunta entonces es ¿qué pasó con aquello que la CONADEP no incluyó en su informe por selección, por omisión, por desconocimiento, por decisión política, moral, de clase? ¿Cómo funciona la verdad del informe frente a las verdades que no fueron o no pudieron ser incluidas? ¿Qué tipo de mecanismos y representaciones de los comisionados se pusieron en juego al elegir los casos a ser relatados y relevados?

Si bien no sabemos los motivos, o en términos más simbólicos las representaciones que esta comisión tuvo a la hora de seleccionar las formas de relato y los recortes elegidos, si podemos analizar qué fue lo que silenció, olvidó u omitió. Antes debemos reconocer que cada uno de estos conceptos tiene su significado dispar pero aquí los usamos como elementos de señalización de aquello que no fue dicho. Inclusive nos interesa el propio concepto de silencio en tanto y en cuanto la propia comisión dice: "si bien debemos esperar de la justicia la palabra definitiva, no podemos callar ante lo que hemos oído, leído y registrado”. (Nunca Más, 1986, p.7).

\section{De-construir el Nunca Más.}

El Informe de la CONADEP tiene seis capítulos. El Capítulo II lleva por título: Víctimas. El capítulo abre con una advertencia sobre las listas confeccionadas, sus limitaciones tanto en lo numérico como en lo territorial. Enumera los casos que se lograron registrar y las debilidades que estos registros pueden tener. A seguir se traducen esos números en unos gráficos por edad, sexo, ocupación, y porcentaje de casos documentados. Vamos a detenernos en dos de esos gráficos. Los mismos ilustran de manera manifiesta cuales fueron las categorías que se incluyeron en torno a lo que se definió como víctimas de la represión. Por un lado, uno de los gráficos muestra la distribución de desaparecidos por profesión u ocupación. El otro, nos relata quienes fueron los desaparecidos según el sexo.

En el gráfico de distribución de desaparecidos por profesión u ocupación la lista es bastante significativa: obreros, estudiantes, empleados, profesionales, docentes, autónomos y varios, amas de casa, conscriptos y personal subalterno de fuerzas de seguridad, periodistas, actores-artistas, etc. y religiosos. Por supuesto que todas las profesiones están enunciadas desde la construcción masculina y en categorías de trabajadores "aceptadas" moralmente desde una mirada de los comisionados. ${ }^{10}$

acusaciones de otros académicos, en torno a que mi texto fue usado en el juicio contra el Ingenio Ledesma a favor de la empresa y no de las víctimas. Este contrapunto puede verse en KarasiK et all (2015).

${ }^{9}$ Para responder estas preguntas sería necesario entrevistar a los protagonistas, recorrer un análisis pormenorizado de los mecanismos, los tiempos, los intereses que estos hombres y una mujer, tuvieron frente a la comisión. También se deberían incluir las visiones que tuvieron comisiones locales de la CONDEP, como las de Córdoba, Mar del Plata, etc. que seguramente permitirían comprender las tensiones entre el centro de la comisión y las acciones más periféricas.

${ }^{10}$ Si bien durante los años ochenta el discurso inclusivo no era una demanda no podemos desconocer que la comisión estaba integrada por una sola mujer, la cual evidentemente no demandó la escritura inclusiva desde las mujeres. Por otro lado, es interesante observar a simple vista que la única enunciación de profesiones "femeninas" sea la de amas de casa. Finalmente sabemos, por lo menos en Córdoba la desaparición de prostitutas durante la dictadura militar que no aparecen en los registros oficiales como una profesión. 


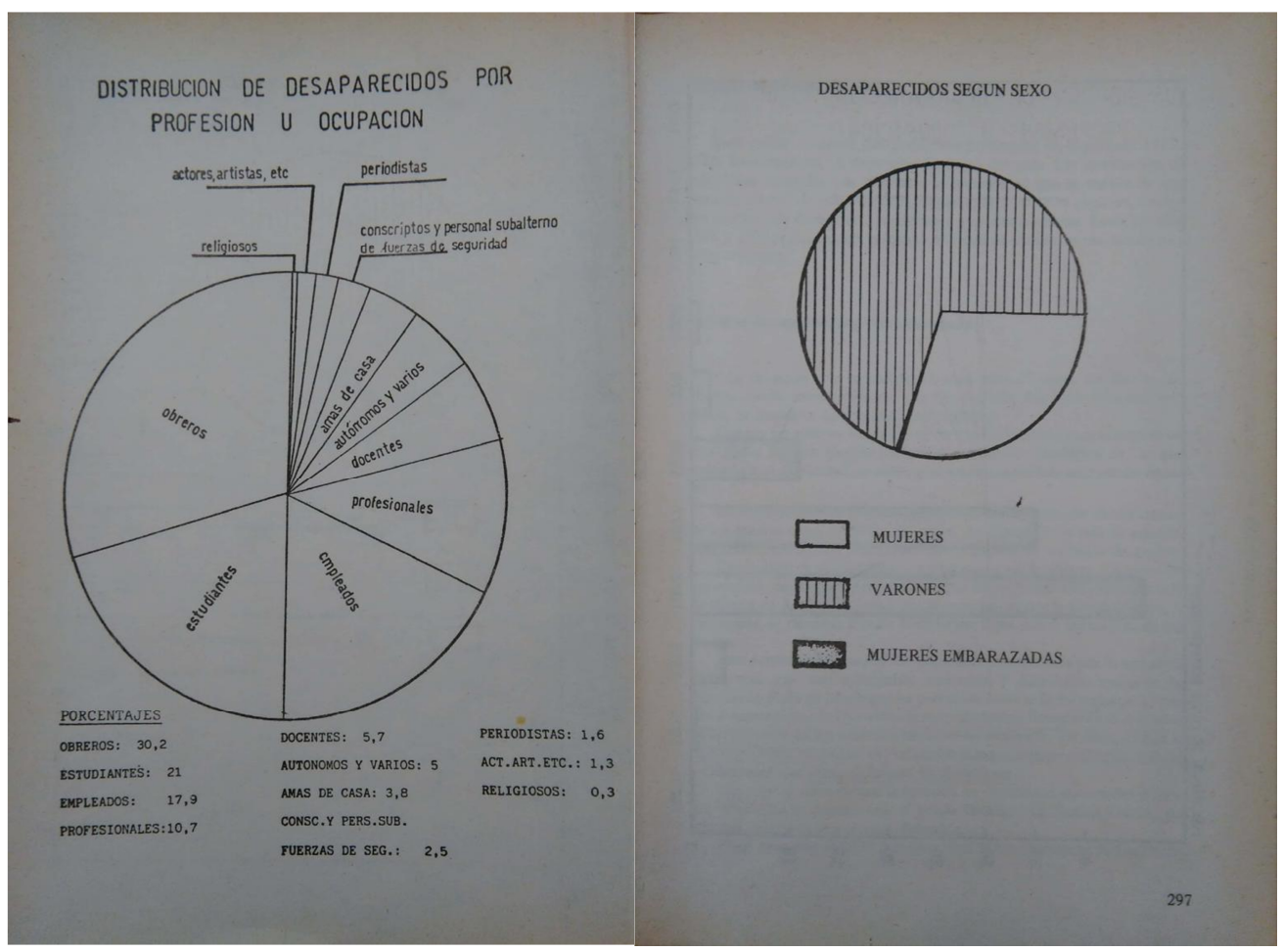

El primer gráfico da cuenta de una mirada construida desde el centro, urbano, clase media, que sin duda deja de lado, silencia, olvida o simplemente desconoce otra diversidad de profesiones u ocupaciones que fueron afectadas por la represión: campesinos ${ }^{11}$, prostitutas, etc. Tampoco se presenta una enunciación por pertenencia étnica, que sería todavía más significativo debido a que en el propio informe dedica, por ejemplo, un apartado especial a la desaparición de judíos (ver páginas 69-78 bajo la denominación de antisemitismo) Se deja de lado así por ejemplo a indígenas, gitanos, extranjeros, etc. Inclusive podríamos pensar que la categoría "religiosos", si bien se enuncia que "la represión ilegal en la Argentina alcanzó a todos y a cada uno de los sectores de la comunidad. Tanto la grey católica como las otras confesiones fueron también protagonistas, a través de sus miembros religiosos o laicos" (Nunca Más, 1986, p. 347), luego en la descripción de las víctimas sólo aparecen casos relativos a la Iglesia Católica y en segundo lugar a religiosos protestantes. Nada se dice de los Testigos de Jehová, sistemáticamente perseguidos durante la dictadura ${ }^{12}$ y mucho menos de aquellos que practicaban religiones afros. ${ }^{13}$

Por otro lado, el segundo gráfico habla del sexo de los desaparecidos, allí sólo se incluyen mujeres, mujeres embarazadas y varones. Hay en esta clasificación una mirada heteronormativa, que sin lugar a dudas "olvida" $\mathrm{y} / \mathrm{o}$ silencia a otros y otras como: homosexuales, lesbianas, travestis.

Podemos decir que en ésta clasificación de la CONADEP de porcentajes de ocupación y

\footnotetext{
${ }^{11}$ Dentro del capítulo de Víctimas, si bien en el cuadro no se enuncia el porcentaje de desapariciones en el mundo campesino, se le dedica un apartado bajo la categoría de Desapariciones del medio laboral agrario, específicamente para enunciar la represión a las Ligas Agrarias.

${ }^{12}$ Desde el año 2012 el juzgado del Dr. Rafecas lleva adelante una investigación de los delitos de lesa humanidad contra los Testigos de Jehová. Esta acción fue promovida por la APDH.

Ver: http://www.infojusnoticias.gov.ar/nacionales/la-persecucion-de-la-dictadura-a-los-testigos-de-jehova-1259.html

${ }^{13}$ Ver: Mariela Analía Mosqueira, "Religión, Identidad y Memoria": relato mnemónico de la comunidad religiosa argentino- africana "Omi O Baba".

http://webiigg.sociales.uba.ar/iigg/jovenes_investigadores/5jornadasjovenes/EJE1/Mesa6_Mosqueira.pdf
} 
de desaparición según sexo, se cuela una mirada clasista y porque no decirlo por omisión, racista (excluyendo de las víctimas al mundo indígena, afro $\mathrm{u}$ otras pertenencias étnicas). Por otro lado, una posición moral y religiosa que distingue sexos pero no sexualidades. Esto está claramente atado a la propia concepción de la Nación argentina en su relato original de civilización versus barbarie. Indios, negros, pobres, "desviados", amorales, locos, atorrantes, quedaban al margen de lo deseable para una nación blanca y europea. Como afirma Osvaldo Bazán en su libro La Historia de la Homosexualidad en Argentina:

La Generación del '80 con su política higienista puso a los "invertidos" bajo la lupa de la ciencia y terminó convirtiendo en delincuentes a todos los "pederastas" del bajo fondo. De esa época es el llamado "depósito 24 de Noviembre", porque estaba ubicado en esa calle. Ahí la policía llevaban a la gente que detenía sin causas penales: anarquistas, prostitutas, inmigrantes, lunfardos, travestis, madamas, homosexuales, bisexuales, los que no estaban invitados a construir el país que pretendía la Generación del '80. Los “científicos” analizaban las "perversiones" de los vagos, atorrantes e "invertidos" de 4 a 20 años. Llegaron a estudiar, incluso, al anarquismo como enfermedad social. Todos esos estudios quedaron registrados en una publicación del Estado de principios de 1900 llamada Archivos de Psiquiatría, Criminología y Ciencias Afines, creada por el doctor Francisco De Veyga -que también era policía- y José Ingenieros. Son el mejor registro que nos ha quedado de la vida marica a principios de siglo. Ingenieros hace un trabajo horrible con 500 canillitas de 4 a 18 años: los acusa de hacer onanismo grupal, pederastia y coito bucal recíproco. Y termina diciendo que hay que tener mucho cuidado porque 10.000 vagos deciden una elección en la ciudad de Buenos Aires. (Bazán, Osvaldo. Historia de la homosexualidad en la Argentina)

Tanto desde la constitución de la nación Argentina, como en las siguientes década la persecución a los homosexuales fue una constante. Cómo analiza Insausti (2019), "desde la década de 1940 y hasta principios del siglo XXI, el Estado argentino se dedicó a perseguir con ahínco a los disidentes sexuales. La experiencia de las maricas en ese tiempo fue de una vulnerabilidad extrema: el mero tránsito por el espacio público las exponía a la posibilidad de ser detenidas".

¿Por qué volver a leer el informe de la CONADEP, de manera de-construida, a modo de comprender los ciclos de memorias y de silencios?

Por un lado, el libro Nunca Más es un lugar de memoria en sí mismo. Narra un inicio y propone una lectura hacia el futuro de lo que el pasado de violencia legó. En este sentido, es imposible no volver a él, ya sea para legitimar memorias ya aceptadas, hegemónicas, dominantes, así como para demandar la visibilización de otras, que por portar menos capitales simbólicos, políticos, culturales o económicos no adquirieron visibilidad en el espacio público. Todas las figuras incomodas, los "individuos peligrosos" fueron- en la investigación de la CONADEP- sistemáticamente silenciados, olvidados o simplemente invisibilizados y así excluidos del relato de esta memoria "encuadrada", aunque fueron perseguidos, asesinados y desaparecidos durante el terrorismo de Estado y en muchos casos ya existían en el momento del trabajo de la Comisión registros y denuncias al respecto.

En el caso de las memorias sobre la diversidad sexual hay una apelación al Nunca Más 
justamente en aquello que no se dijo, se silenció, se negó. Cuando se intenta reconstruir la violencia sobre los cuerpos de homosexuales, lesbianas, travestis y prostitutas se recurre una y otra vez al mismo relato que enuncia el reclamo por los 400. Aparece así una figura central que es la de Carlos Jauregui y su libro La Homosexualidad en Argentina (1987), donde se cristaliza un párrafo que une el relato de la CONADEP al silencio sobre desaparición y diversidad sexual. Este "emprendedor de memoria" (JELIN, 2001) hizo de su militancia y activismo constante una bandera para visibilizar lo que la CONADEP omitió.

Carlos Jáuregui, en La homosexualidad en la Argentina, cuenta que uno de los responsables de la Conadep le afirma la existencia de por lo menos 400 homosexuales integrando la lista del horror. Y dice que "el trato que recibieron fue similar al de los compañeros judíos desaparecidos, especialmente sádico y violento". Esto no se contó en el Nunca Más. Mucho tiempo después, Jáuregui contó que el rabino Marshall Mayer le había admitido que esa escandalosa omisión se habría debido a las presiones del ala católica de la Asamblea Permanente por los Derechos Humanos. (Bazan, Osvaldo. Historia de la homosexualidad en la Argentina).

Este relato, proveniente de una charla con uno de los integrantes de la CONADEP, se transformó en un testimonio legitimado para construir un núcleo narrativo, a partir del cual comenzar a demandar la inclusión de las memorias sobre la diversidad sexual y la represión en Argentina. Aquellas memorias subterráneas, que se mantuvieron fuertes dentro de comunidades de afectos, de luchas políticas y de reivindicaciones contra la hegemonía de memorias hetero normativas, comenzaron a fluir en el espacio público. Esto demuestra también que lo que el Estado omitió, siempre estuvo presente en el relato de este colectivo y sus luchas políticas.

Si tomamos el informe de la CONADEP como eje de lo invisible y lo visible, lo dicho y lo no dicho es interesante analizar que pasó antes y que pasó después de la instauración de esta memoria encuadrada en la letra escrita del libro Nunca Más. Esta memoria encuadrada luego se cristalizó y fortaleció en la construcción de una memoria dominante de los organismos de derechos humanos en Argentina, dónde la centralidad de la familia y los lazos primordiales de la sangre constituyeron el núcleo duro de la legitimidad de las memorias en el espacio público.

Lo primero que suelo recalcar a la hora de hablar sobre lo sucedido con la población LGTB y la invisibilización de las militancias, organizaciones y violencias ejercidas sobre nosotres, es a mi entender el eje que sustenta uno de los pilares de la memoria: la familia. Hemos construido un casi "sacrosanto" símbolo de lucha: los pañuelos blancos, esos que en un comienzo fueron los pañales que las madres se pusieron sobre sus cabezas. Dificil es analizar este movimiento sin ofender y cuestionar uno de los símbolos más fuertes que existen en nuestro país. Pero, no dejo de ver en este movimiento que tanto ha hecho por la conquista de algunos derechos, un efecto colateral del cual no hemos podido escapar. Familiares de desaparecidos, madres de desaparecidos, saliendo, conquistando espacios, cargándolos de simbología. Y les desaparecides pasaron a ser los hijos de madres luchadoras, desaparecidos deseando formar esas familias, con hijes, nietes de aquellas mujeres heterosexuales, hijos de desaparecides heterosexuales. Se legitimó la imagen de la familia con esos valores morales, cis normados en les desaparecides y las 
familias de aquellos que salieron a pedir juicio y castigo. Fuera de esos pedidos, de esos relatos, del ejercicio de la memoria estuvieron y están los que no encuadran esta construcción simbólica del pañuelo blanco. (Eugenio Talbot, en diálogo para la elaboración de este texto).

\section{Memorias subterráneas, memorias diversas}

Volvamos nuestra mirada hacia el pasado para comprender este presente. Los años sesenta y setenta fueron momentos de creación de organizaciones que llevaban adelante la lucha sobre la diversidad (sin usar este nombre) a partir de núcleos que identificaban a sus integrantes desde sus elecciones sexuales y en torno a las denuncias de persecución. Específicamente estas organizaciones tenían entre sus demandas, la denuncia de las acciones policiales a partir de la aplicación de los edictos policiales que - nacidos en la década del 30-perseguían y encarcelaban a homosexuales y travestis con 21 días a 28 días de prisión cuando eran reprimidos en las vía pública.

Estas memorias fueron constituyéndose poco a poco y dejando una marca profunda en publicaciones y archivos, sabedores de la eficacia simbólica de la cultura escrita, del poder qué la palabra impresa tiene como soporte de preservación hacia el futuro. Tornando visibles sus acciones en el espacio público y en la demanda de ser incluidos en luchas políticas más amplias y formales.

La creación de la organización Nuestro Mundo en 1967 (fundada por Héctor Anabitarte, dirigente sindical y ex militante del PC expulsado del partido por su orientación sexual); la formalización del Frente de Liberación Homosexual en 1971 (Manuel Puig, Juan José Sebreli, Nestor Perlonher, Héctor Anabitarte, entre otros); la creación de la Revista Somos (diciembre de 1973) y del documento Sexo y Revolución (1973) marcaron el inicio de voces plurales para dar cuenta de las luchas LGTB en Argentina. En el proceso de conformación del Frente también se unieron con la Unión Femenina Argentina (UFA), Safo, el Movimiento de Liberación Feminista (MLF) y la Asociación de Mujeres Socialistas. Es interesante notar que, dentro de estas memorias, hay mucha más visibilidad de aquellas que relatan las acciones del Frente de Liberación Homosexual y sus integrantes masculinos, que las memorias de las mujeres lesbianas. ${ }^{14}$

Como parte de una narrativa que constituye la memoria de las acciones desde la diversidad sexual se relata una y otra vez dos episodios del FLH en el espacio público, que a pesar de la osadía de quienes los conformaron tuvieron poco apoyo en la esfera de la política formal. El FLH estuvo presente en la Plaza de Mayo, en mayo de 1973, en la asunción de presidente Cámpora (25 de mayo de 1973-13 de julio de 1973). Llegó a la mítica plaza con su bandera la cual tenía estampada una frase perteneciente a la marcha peronista ${ }^{15}$ : "Reine en el pueblo el amor y la igualdad". Si bien en los testimonios de algunos de los integrantes del FLH, recuerdan que en la plaza muchos se solidarizaron con su causa, otros resaltan el rechazo que sufrieron a través de la consigna cantada por militantes peronistas ${ }^{16}$ : "No somos putos, no somos faloperos, somos soldados de Evita y Montoneros".

\footnotetext{
${ }^{14}$ Puede consultarse sobre este tema el trabajo de Equipo de potencia tortillera (2019)

${ }^{15}$ La Marcha Peronista, en su versión más conocida y popular de "Los muchachos peronistas" fue grabada por Hugo del Carril en 1949. El propósito era difundirla para la celebración del 17 de octubre de ese año, fecha establecida como Día de la Lealtad.

${ }^{16}$ En la historia del peronismo la persecución a los homosexuales se inició en el primer gobierno con la incorporación en los edictos policiales del inciso 2o "H". Este inciso se siguió utilizando casi cuarenta años desde su creación.
} 
Durante la primavera camporista, la persecución a los homosexuales cesó de manera significativa. Sin embargo, a partir de la creación de la triple A (octubre de 1973) y el dominio de la derecha peronista con López Rega, el FLH registró claramente los prolegómenos del terrorismo de Estado. Un documento de época alertó a la comunidad homosexual lo que estaba por venir. En 1975 aparece el documento, "Acabar con los homosexuales" de la revista El Caudillo ${ }^{17}$, del 12 de febrero de $1975,{ }^{18}$ planteaba abiertamente que los "maricones deben ser erradicados de nuestra sociedad (...) hay que terminar con los homosexuales, encerrarlos o matarlos" (p. 62).

\section{LO VERDADERO Y LO FALSO}

\section{AGABAR GON LOS HOMOSEXSUALES}
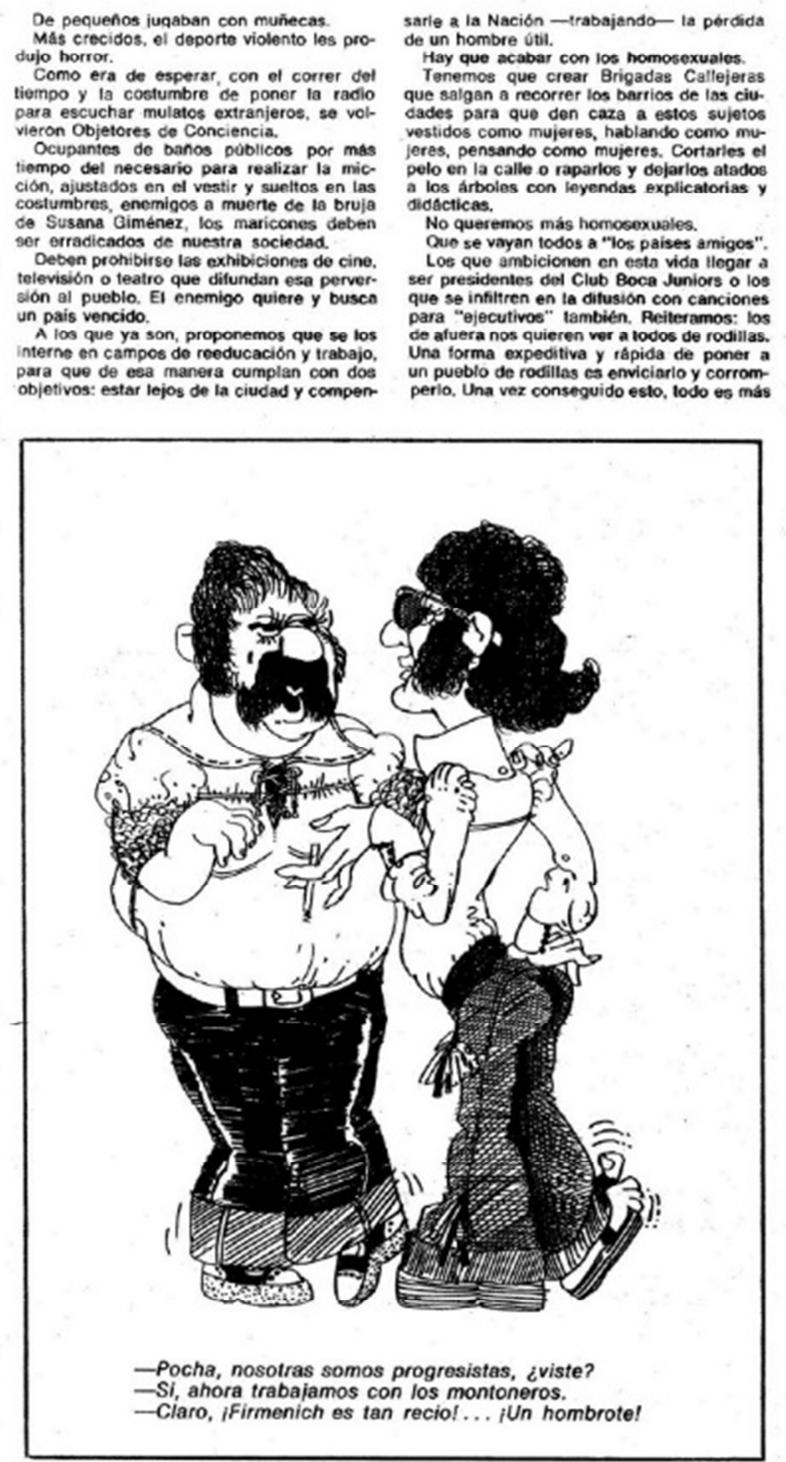

16 ELGATILO

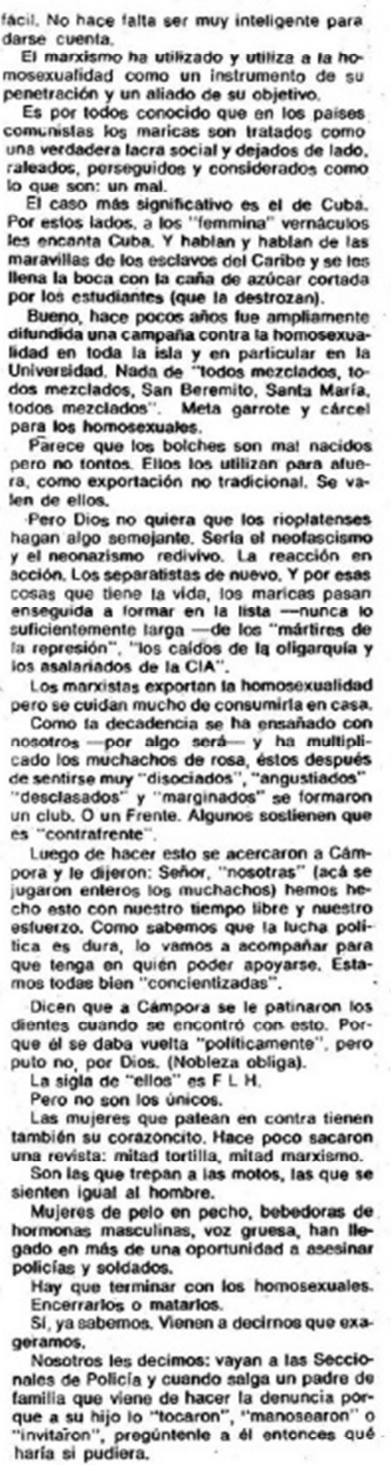

"invitaron", progúntento "manosearon" haría si puciera.

\footnotetext{
${ }^{17}$ Las Revistas El Caudillo pueden ser consultadas en el archivo virtual Ruinas Digitales http://www.ruinasdigitales.com/el-caudillo/

${ }^{18}$ Órgano de difusión de la Juventud Peronista de la República Argentina, Comando de Organización, la Juventud Sindical Peronista y la Alianza Anticomunista Argentina, Ministerio de Bienestar social.
} 
El FLH, en respuesta este artículo, escribió un documento donde expresa su rechazo y plantea que atenta contra los más elementales derechos humanos. Definen que la violencia fascista pretende imponer un modelo autoritario de conducta que contradice la libre elección de la persona humana, "los ideólogos del fascismo criollo reivindican para si su "viril" derecho a matar". Para El Caudillo amar a una persona del mismo sexo es suficiente para desatar el genocidio. Hoy callar es también mentir. La indiferencia es la complicidad”.

\section{El Fascismo nos amenaza}

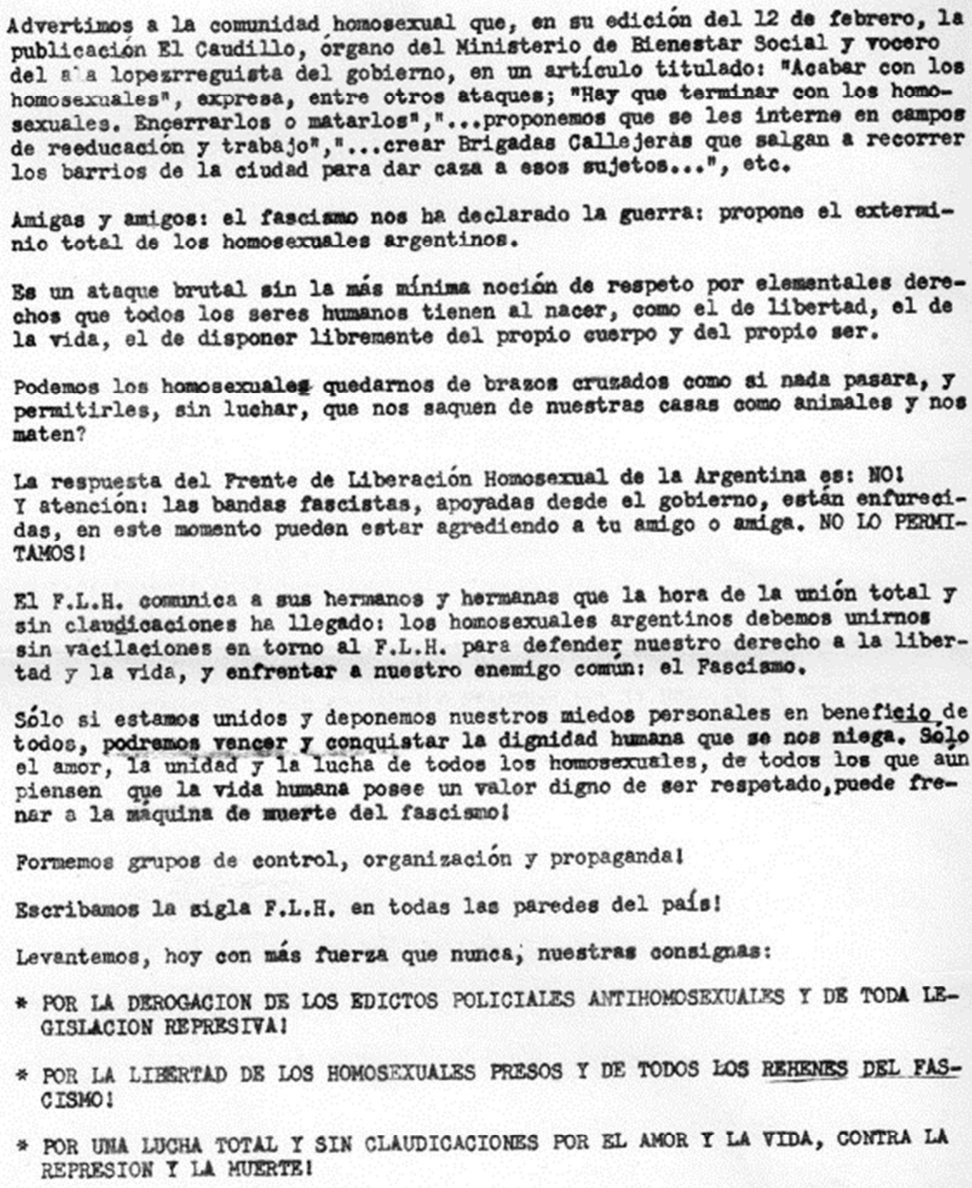

\section{FRENTE DE LIBERACION HOMOSEXUA L}

DE LA ARGENTINA

Ahora bien, el FLH se creó en función de ideas, demandas y reivindicaciones en torno a las necesidades de una comunidad determinada. En su génesis primero las organizaciones de izquierda y luego el peronismo conformaban los ejes políticos de sus reivindicaciones. Su propia 
construcción identitaria tomó aspectos del peronismo para disputar sentidos en la esfera pública, como ya señalamos, a partir de la consigna de su bandera que conformaba parte de la letra de la marcha peronista. Sin embargo, cuando se recorre y lee la letra, la misma está cargada de referencias heteronormativas asociadas a la figura de Perón. La estrofa que sigue unos renglones más abajo de la elegida por el FLH "reine en el pueblo el amor y la igualdad", afirma: "Imitemos el ejemplo de este varón argentino" en referencia a Perón. Lo que queremos expresar aquí, es que el mismo sistema simbólico al que apeló el FLH para construir su genealogía, sus memorias, su identidad: los símbolos peronistas, la plaza de mayo, la apelación a ser incluidos en el partido, fueron los mismos con los que los atacaron, persiguieron hasta afirmar que se debía "acabar con los homosexuales". Así la Revista Somos y El Caudillo construyeron dos visiones de mundos distantes, contrapuestas, en conflicto, pero dentro de un mismo campo político.

Antes de la llegada de la dictadura de 1976, había una extensa gama de prácticas estatales discriminatorias y persecutorias hacia el mundo homosexual. Por un lado, los jóvenes que debían hacer el Servicio Militar Obligatorio sufrían todo tipo de humillaciones en la revisación médica lo que quedaba grabado con un OAD en su DNI, marcando su condición de homosexual. También la Ley de 1946, llevada adelante en el gobierno del Coronel Domingo Mercante, establecía que en la provincia de Buenos Aires los homosexuales no podían votar (ley que se derogó recién en el año 1987). ${ }^{19}$ Así como ya vimos, en diferentes contextos y épocas de la historia Argentina, la persecución a la comunidad homosexual fue una constante y no una excepción. De esta forma, no es la dictadura la que inaugura la persecución a los homosexuales, sino que continúa con prácticas instaladas tanto en la legislación como en las formas represivas policiales. Si durante la dictadura homosexuales, prostitutas y trans fueron encarcelados y asesinados, esto no fue una novedad para cuerpos castigados y perseguidos por décadas. Las fuerzas policiales siguieron también usando los mismos mecanismos que ya eran habituales desde la década del 30 .

Con la llegada de la dictadura, en los centros clandestinos de detención, ser judío o ser homosexual era un plus de estigma que se sentía en la tortura. La pregunta que se hacen algunos investigadores es si el motivo de las detenciones era la "homosexualidad" o la pertenencia política, ya que no hay evidencias de que fuese por lo primero. O sea una discusión basada en el origen de la represión, en donde el planteo es si las personas, eran secuestradas por lo que "hacían" o por lo que "eran". Esta distinción puede colocarnos frente a una trampa analítica. Lo que es importante remarcar es que hay un proceso de continuidad en la represión a los homosexuales, sea en democracia o en dictadura, dónde lo que prevalece es la idea de lo "desviado" que debe encaminarse, curarse y en el extremo eliminarse.

La acción burocrática del Estado represor dejó huellas de su mirada sobre los homosexuales, las prostitutas. Estas acciones quedaron documentadas en los archivos policiales y militares. La continuidad en las formas represivas no sufrió ninguna ruptura y quedó plasmado en diversos documentos de inteligencia como los que hoy están custodiados en el archivo DIPBA.

\footnotetext{
${ }^{19}$ Técnicamente, lo que la ley prevé es que puede declararse nulo el voto de quien sea sujeto de un certificado médico de insania mental o del ciudadano que haya sido sentenciado en firme por conducta inmoral relativa a la homosexualidad.

Ver: https://elpais.com/diario/1987/01/30/internacional/538959620_850215.html
} 


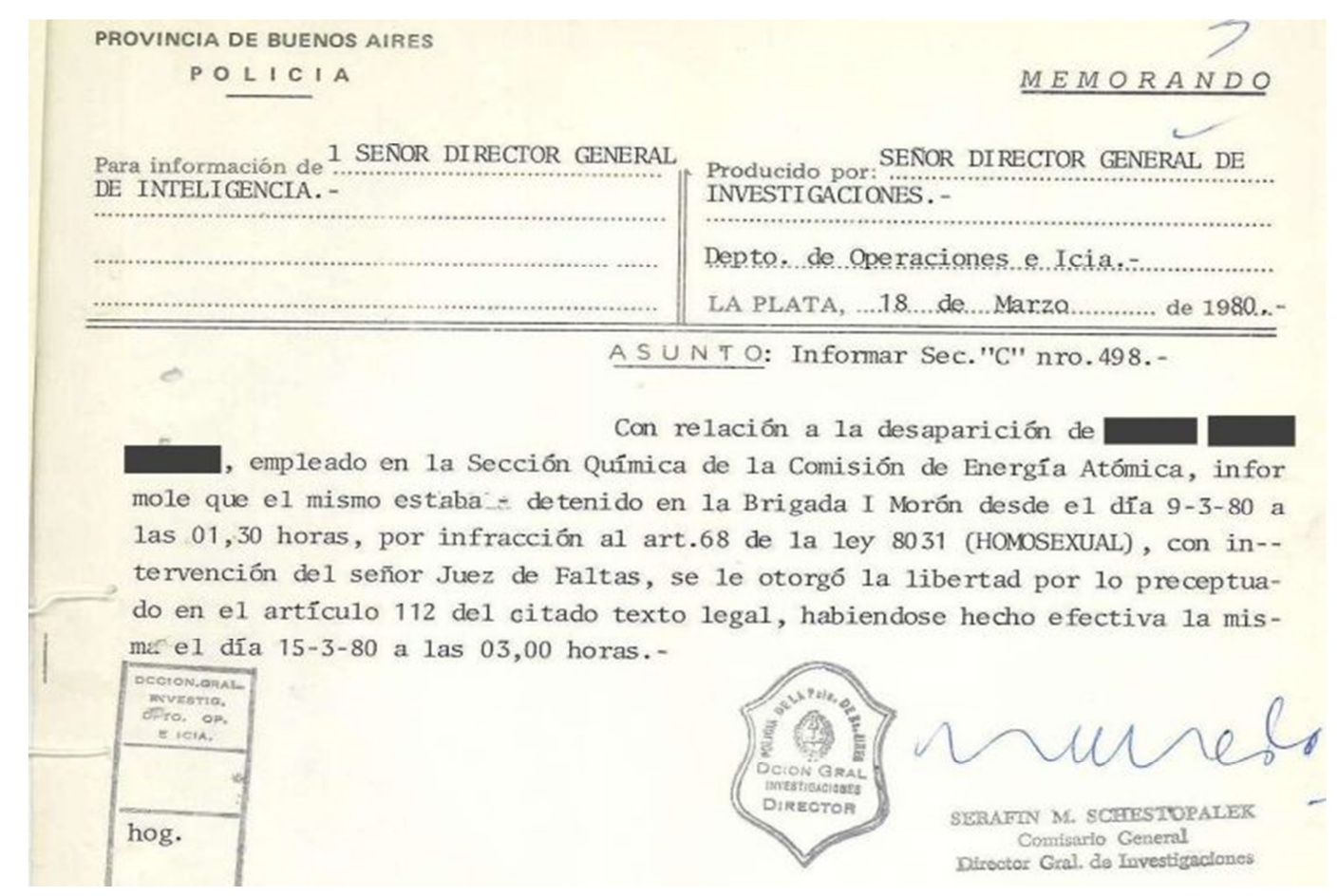

La pregunta que podemos hacernos entonces es ¿cuáles fueron las condiciones para que estas memorias, que siempre circularon subterráneamente, se tornen comunicables después de la dictadura?

\section{Memorias reb(v)eladas, insurgentes.}

Como sabemos todo testimonio pone en juego no solamente la memoria, sino también la reflexión sobre uno mismo. Hablar, callar, ser escuchado no depende únicamente de la voluntad o de la capacidad de los testigos de reconstruir su experiencia y querer transmitirla, sino de un campo de posibilidades que permita romper el silencio, desarmar los no dichos, construir legitimidades que hagan transmisibles su testimonio. De esta manera, tanto la memoria como el silencio se anclan en las condiciones sociales que lo vuelven comunicable y por ende audibles. Evidentemente, durante la transición democrática, cuando la CONADEP puso en marcha su informe no estaban dadas las condiciones de escucha para incluir las denuncias a las violaciones a los derechos humanos de la comunidad homosexual, lésbica, trans y de prostitutas. Este "olvido" por parte del Estado tuvo tanto razones políticas como morales y entraron en tensión la imagen oficial del pasado de una nación con las experiencias y dolores personales. Por otro lado, muchos de estos recuerdos eran "indecibles" para los propios individuos que habían vivido la tortura sobre sus cuerpos por "ser" homosexuales o prostitutas. Sabemos que hacia el fin de la dictadura no hubo un corte abrupto con lo que socialmente se "pensaba" de la homosexualidad, las prostitutas, los trans y lesbianas. Otros y otras también pueden haberse silenciado por vergüenza y pudor de expresar sus experiencias de vejámenes durante la dictadura, al haber sido sometidos a la violación como forma de tortura. Tabú este que no sólo se dio en esta comunidad sino en todo aquel y aquella que pasó por un CCD y fue violado o violada. En este sentido podemos pensar junto con Pollak (1996), que en el caso de las memorias de aquellos que comparten la mirada de una sexualidad diversa el silencio tiene muchas razones. Puede estar dado por la angustia de no encontrar una escucha; ser sancionado 
moralmente por lo que se dice o para no exponerse a malentendidos.

¿Cuándo y porqué estos silencios se rompen? ¿Cuándo memorias al margen rompen sus espacios subterráneos y ocupan la esfera pública? En relación a lo que analizamos, para el caso Argentino, este silencio se rompió junto a una serie de políticas de Estado. La posibilidad del cambio de sexo mediante operación, por la Ley de Identidad de Género (2012) y el decreto 903/2015 que reglamenta las cirugías para el cambio de sexo y los tratamientos hormonales para "adecuar el cuerpo" y la rectificación registral del sexo y el cambio de nombre de pila e imagen en la partida de nacimiento y en el DNI a través de un trámite en el Registro Civil. Por supuesto, la ley 26618/10, que regula el matrimonio igualitario, estableciendo que tendrá los mismos requisitos y efectos, con independencia de que los contrayentes sean del mismo o de diferente sexo. El Estado reconoce así la diversidad sexual, con jurisprudencia compleja y sobre todo porque en cada caso hubo un ser humano dispuesto a dar esas batallas que benefician a toda una comunidad. Allí también "explotan las memorias insurgentes". No ya en la calle con esa primera bandera en la Plaza de Mayo de 1973, sin cuya experiencia las de hoy no tendrían fuerza, sino en la demanda al Estado del reconocimiento pleno de ciudadanos y ciudadanas con derecho a sus identidades de género.

Hubo dos momentos en estos últimos años que permitieron observar también el quiebre del silencio sobre el pasado reciente. Por un lado, el proyecto de Ley nacional "Diana Sacayan", que se ocupa del cupo laboral para personas travestis, transexuales y transgéneros en el sector público nacional. Durante la redacción del mismo se incluyó la siguiente afirmación:

Los resabios de la oscura etapa de la dictadura cayeron con crueldad sobre este colectivo a través de la creación de figuras jurídicas que criminalizaban la diversidad de las identidades de género, modelo que incluso continuó durante la democracia. Ser travesti, transexual o transgénero en Argentina era, hasta hace apenas unos años estar condenadxs a distintas prácticas de persecución sistemática, represión, discriminación y exclusión social. https://www.diputados.gov.ar/proyectos/proyecto.jsp?exp=4033-D-2018

Por otro lado, a partir del año 2018, el gobierno de la Provincia de Santa Fe llevó adelante una reparación histórica, hasta el momento la única del país, a once mujeres rosarinas y cuatro de la ciudad de Santa Fe. Las mismas fueron reconocidas como "presas politicas en razón de su identidad de género". Carolina Boetti de Rosario, 55 años, actriz, fue la primera mujer trans en el país en acceder a la pensión que se otorga a víctimas de la dictadura, ${ }^{20}$ en el marco de la Ley Provincial 13.298 de la provincia de Santa Fe.

\footnotetext{
${ }^{20}$ A partir de esta lucha se montó una obra de teatro. Finalmente Reparadas es consecuencia de un hecho que ocurrió hace muy poco en la provincia de Santa Fe (2018), donde el Gobernador Miguel Lifschitz reconoció a las MUJERES TRANS víctimas de la última Dictadura Militar. Mujeres sobrevivientes de una generación marcada por el exilio, la desaparición y la muerte; víctimas de un accionar político que accionó con particular ensañamiento la persecución y represión hacia ellas.

Esta obra recorre las vidas y violencias que padecían estas mujeres en los años 80 , década de la que pudieron sobrevivir queriendo ser quienes ellas quisieron y dejando así un precedente para la historia rosarina y santafesina. Brillos, escándalos, policías, amigas intachables, complicidad, droga, corridas, moralidad, códigos contravencionales, noches, prostitución, belleza única hicieron que hoy llamamos a estas mujeres sobrevivientes de la vida... sobrevivientes de la peor época de la Argentina.

https://www.plataformalavarden.gob.ar/actividad/finalmente-reparadas/
} 
Estoy muy feliz porque se hizo justicia. Mi historia es la de muchas mujeres trans que sufrieron la dictadura, donde nos detenían y éramos víctimas de violencias y aberraciones. Esta pensión es una reparación histórica. Se me cruzaron muchas emociones porque me la entregaron en el mismo lugar donde fui detenida. Nunca más.

(http://agenciapresentes.org/2018/05/18/por-primera-vez-el-estado-repara-auna-trans-sobreviviente-de-la-dictadura/).

A esta apertura pública de memorias insurgentes relativas a los derechos conquistados y reconocidos por el Estado se suma también las prácticas más simbólicas que pretenden ganar espacio en el complejo sistema de memorias dominantes en el mundo de los derechos humanos. La marcha del 24 de marzo es, en Argentina, un escenario dónde se convalidan memorias, se abren posibilidades de diálogo, se comparten experiencias y se amplía o achica, a cada año, los sentidos de esa comunidad política. La bandera de la diversidad sexual, así como la wipala u otras manifestaciones sobre el amplio abanico de diversidad sean sexual, étnica, política o religiosa siempre ha ocupado un espacio territorial en la marcha. Han sido cobijadas dentro de la noción de lucha por los derechos humanos. Sin embargo, a más de 40 años del fin de la dictadura militar poco se ha hablado del dominio heteronormativo de la memoria. Allí la comunidad LGTB comenzó a disputar sentidos en torno a los modos, formas y legitimidades con las que se ha venido construyendo la memoria en Argentina.

Como en todo escenario de disputas, dos acciones pasaron a ser constitutivas y constituyentes de estas disputas. Por un lado, una nueva bandera y un número. Por otro, una nueva consigna que disputa sentidos sobre un mismo substrato cultural y político de acciones por los sentidos del pasado.

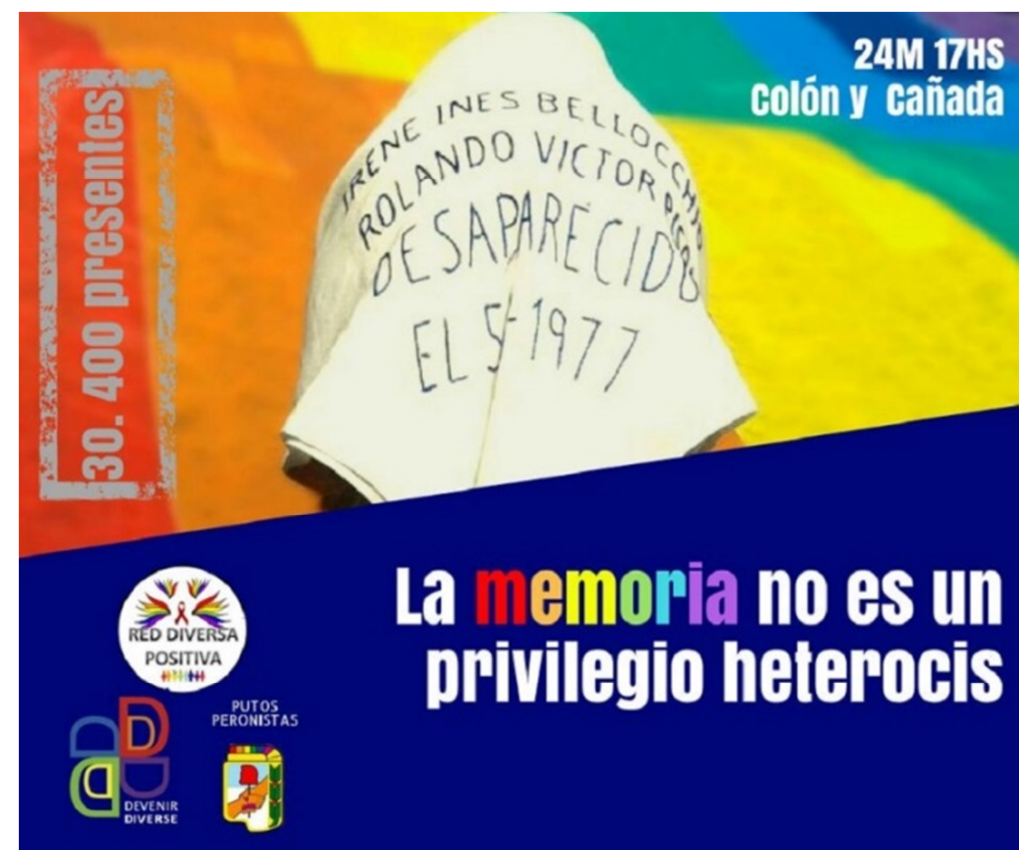

La memoria no es un privilegio heterocis fue la consigna llevada adelante por la comunidad LGTB de Córdoba en la 43a Marcha del 24 de Marzo, interpelando de manera frontal a las memorias de los organismos de derechos humanos locales. Por otro lado, se inscribe, en tanto marca y huella, 30400 presentes retomando una larga demanda de reconocimiento de los 
desaparecidxs pertenecientes a la comunidad que no fueron incluidos en el gran relato del Nunca Más. Como afirma Greta Pena, directora del colectivo 100 \% Diversidad y Derechos:

Queremos visibilizar a lxs 400 compañeros LGBTI desaparecidxs que fueron borrados de la CONADEP por influencia de la Iglesia Católica. Son nuestros 400 dentro de los 30000 desaparecidxs.

(https://agenciapresentes.org/2019/03/24/memorias-lgbt-en-dictadura-en-laclandestinidad/

Ahora bien toda lucha por la memoria no se da sin conflictos y la bandera de los 30400 es cuestionada y debatida. Como dice Eugenio Talbot,

Comienzo a plantearme como las sociedades y organizaciones necesitan de símbolos. Pañuelos, espacios, monumentos, números. Y cuando un nuevo símbolo surge como una necesidad, parece que compitiese con el anterior. La violencia ejercida por los organismos de derechos humanos ante el 30400 es escandalosa. La hegemonía en la construcción de la memoria sigue en mano de familiares con todo lo que esto implica. Y los que fueron negados por sus padres, los que vivieron situaciones conflictivas con ellos, los marginalizados por su sexualidad o identidad de género, los sin HIJOS, perdimos el derecho de participar activamente. Nos relegaron a los márgenes... de los cuales no podemos escapar. (Eugenio Talbot en diálogo para la elaboración de este texto)

Es muy interesante pensar como estas demandas ganan visibilidad a través de memorias insurgentes que disputan sentidos dentro del mismo sistema simbólico ya establecido (pañuelos, banderas, números). No quieren ser más memorias al margen. Quieren formar parte del relato de las experiencias límites que esta nación vivió durante el Terrorismo de Estado. Así el pañuelo blanco, junto a los 30400 presentes, incluye y empuja a pensar cuantas otras memorias siguen silenciadas y deben disputar sentidos para ser oídas e incluidas. Usar la noción de memoria representada con los colores de la bandera de la diversidad sexual es incluirse en una génesis de luchas por los derechos humanos. Y usar el pañuelo blanco de las Madres de Plaza de Mayo ilustrando la convocatoria a la marcha, es apropiarse de un símbolo que es de todos, todas y todes.

\section{Para cerrar}

Entre la presencia en la Plaza de Mayo de la primera bandera del FLH en 1973 y la última marcha del 24 de marzo de 2019, pasaron 46 años. Entre el documento del FLH que reivindicaba el derecho a vivir frente a los ataques fascistas que decretaban la muerte de los homosexuales y las actuales reivindicaciones de la comunidad LGTB se rompieron muchos silencios y tabués. Se conquistaron derechos a partir de una lucha sostenida y constante.

Los sentidos del silencio y su esfuerzo de comprensión como relación y no como substancia, puede observarse en uno de estos ciclos de memorias. Frente a las masacres, tragedias, catástrofes el silencio adquiere un sentido político y enfrenta a los individuos a la demanda de decirlo todo, denunciar, hablar, silenciar u olvidar. Esto no significa que silencio se oponga a memoria, ambos procesos no son contrarios sino complementarios como lo analizamos en relación a la comunidad LGTB. En este sentido, al recorrer un caso particular de 
disputas por los sentidos del pasado, es posible distinguir politicas del silencio donde lo no dicho traduce diferentes maneras de expresión, como una estrategia frente a la saturación de memorias dominantes o como una condición necesaria para mantener la comunicación con el entorno y evitar los malentendidos. El silencio en su uso político expresa acciones y prácticas que unen o separan, revelan o disimulan, marcan acuerdos o profundizan conflictos, limitan fronteras o definen comunidades de pertenencias y de afectos. Así, como en el recorrido propuesto, el silencio ligado a las acciones políticas del colectivo LGTB, representó tanto prácticas que simbolizaron el respeto por el "otro" tanto como la denuncia de injusticias o situaciones de impunidad.

Como afirma Eugenio Talbot Wright,

Pienso en el trabajo de la memoria como un ejercicio colectivo. Hemos trabajado sobre obreros, estudiantes, sindicalistas, militantes de las "reconocidas" organizaciones revolucionarias en conjunto. No fue necesario ser obrero para investigar y trabajar sobre las víctimas de ese sector de la población. De igual forma con los otros grupos de víctimas. Pero sobre la población LGTB nadie ha hablado. Hemos sido nosotros lo que hemos salido a luchar por ser reconocidos y esa lucha ha implicado que organizaciones de todo tipo encontraran el pretexto justo para lavarse las manos. "Que ellos mismos hablen de sus muertos y militantes". Pero podemos hablar solo en algunos lugares, lejos de muchos escenarios, espacios, territorios. (Diálogo con Eugenio Talbot, para la elaboración de este texto)

Esta ruptura del silencio se cristalizó en la demanda de ampliación de las memorias dominantes, dónde las luchas del colectivo LGTB pasen a ser incluidas como una forma de ruptura del monopolio de la memoria heterocis. Esto se plasmó de manera gráfica en la reivindicación de la consigna 30.000 desaparecidos, por la de 30400 desaparecidxs. La disputa por el número pone en evidencia las tensiones que de alguna manera quedaron plasmadas a partir del relato del Nunca Más. Sin embargo, el número sólo cobrará su verdadero sentido cuando pasa a contener los nombres, rostros e historias de esos 400 seres humanos que fueron despojados de sus derechos a ser incluidos en el Informe del Nunca Más. Reivindicar esas memorias, la verdad sobre el silencio y luchar por una verdadera justicia que visibilice las luchas del pasado potencia el presente, dónde la violencia a la comunidad LGTB no ha cesado. Así 30.400 como consigna de lucha, sirve para para "iluminar" lo que pasa hoy con la comunidad LGTBIQ. Los hechos del pasado, que no pasan, deben ser juzgados como delitos de lesa humanidad y los del presente, visibilizados frente a los asesinatos y violencias que hoy sufre la comunidad LGTB.

\section{Bibliografía}

BAZAN, O. Historia de la homosexualidad en la Argentina: de la conquista de América al siglo XXI. Buenos Aires: Marea editorial, 2004.

CRENZEL, E. La historia política del Nunca Más. La memoria de las desapariciones en la Argentina. Buenos Aires: Siglo XXI, 2008.

DA SILVA CATELA, L. No habrá flores en la tumba del pasado. La Plata: Ediciones Al Margen, 
2001.

DA SILVA CATELA, L. Apagón en el Ingenio, escrache en el Museo. Tensiones y disputas entre memorias locales y memorias oficiales en torno a un episodio de represión de 1976. En: DEL PINO, P.; JELIN, E. (comp.). Luchas locales, comunidades e identidades. Madrid: Siglo Veintiuno, 2003.

EQUIPO Potencia Tortillera. Potencia Tortillera: memorias del activismo lésbico en primera persona. Aprendizajes y desafíos del archivo digitalizado del activismo lésbico en Argentina. Dossier: Memorias desde las disidencias sexo-genéricas. Preguntas incómodas para desmontar el cisexismo heterosexual. Revista Aletheia. vol. 10, n. 19, 2019. Disponible en: <https://www.aletheia.fahce.unlp.edu.ar/article/view/ALEe027>

KARASIK, G. A.; GÓMEZ, E. L. Gómez. La empresa Ledesma y la represión en la década de 1970. Conocimiento, verdad jurídica y poder en los juicios de lesa humanidad. Clepsidra. Revista Interdisciplinaria de Estudios sobre Memoria, n. 3, marzo 2015, pp. 110-131, 2015. Disponible en:

<http://ppct.caicyt.gov.ar/index.php/clepsidra/article/view/KARASIK\%2C\%20G\%C3\%93M $\mathrm{EZ} /$ pdf_1>

INSAUSTI, S. Una historia del Frente de Liberación Homosexual y la izquierda en Argentina. Revista Estudos Feministas, vol.27 n.2 Florianópolis, 2019. Disponible en: <https://www.scielo.br/scielo.php?script=sci_arttext\&pid=S0104-026X2019000200213>

JELIN, E. Los trabajos de la memoria. Madrid y Buenos Aires: Siglo Veintiuno de España y Argentina Editores, 2002.

POLLAK, M. Memoria, silencio y olvido. La construcción social de identidades frente a las situaciones limite. La Plata: Al Margen Editorial, 2006.

Recebido em: 18/05/2020

Aceito em: 12/07/2020 